\title{
Biomedical waste management practices at a paediatric tertiary care hospital of Kashmir valley
}

\author{
S. Muhammad Salim Khan', Sheikh Mohd Saleem ${ }^{2, *}$, Mohsina Mukhtar ${ }^{3}$, Ruqia Quansar ${ }^{4}$ \\ ${ }^{1}$ Professor and HOD, ${ }^{2-4}$ Demonstrator, Dept. of Community Medicine, Government Medical College, Srinagar, Jammu \& Kashmir, India
}

*Corresponding Author: Sheikh Mohd Saleem

Email: saleem.900@gmail.com

\begin{abstract}
Introduction: In healthcare settings, where patient care is carried out, a certain type of waste is generated which has the potential to put humans and environment to the risk of infectious diseases and environmental pollution respectively.

Objectives: The present study has been embraced to survey the information regarding Bio-Medical waste among the staff a tertiary care paediatric hospital in Kashmir valley (J\&K).

Materials and Methods: Paediatric hospital associated with GMC Srinagar was visited by a team of public health specialists. A total of 25 interviews were conducted in which five doctors, five staff nurses, five pharmacists, five laboratory technicians and five sanitary personnel participated. The data was acquired from the respondents through a pre-outlined pre-tested survey questionnaire with respect to Biomedical Waste Management and Handling guideline 2016.

Results: The awareness and knowledge about current BMW guidelines 2016 was highest among Laboratory technicians and sanitary personals. The sanitary personals had also better awareness about existing operational guidelines in the hospital and proper waste disposal methods.

Conclusion: The sanitary personals and laboratory technicians were seen to be great in theoretical knowledge of rules, legislations and public health importance of BMW management rules 2016. While for doctors and nursing staff, the reverse was true.
\end{abstract}

Keywords: Biomedical waste, Management, BMW Guidelines, Hospital Survey, Waste management in Hospital.

\section{Introduction}

In healthcare settings like primary, secondary or tertiary care, where patient care is carried out, a certain type of waste is generated which has the potential to put humans and environment to the risk of infectious diseases and environmental pollution respectively. The waste may include soiled cotton, soiled bandages, hypodermic needles, injection syringes, non-degradable tubing's such as intravenous fluids sets, angiocaths, drainage tubes and urinary catheters etc. Such waste is commonly called as bio-medical waste (BMW) especially in India, though clinical waste, medical waste, and health-care waste are synonymous terms used in different parts of the globe. Biomedical waste (BMW) is squander created amid analysis, treatment or vaccination of people or animals, or in investigating exercises relating thereto, or in the creation and testing of biologicals, and is debased with human liquids. ${ }^{1}$ The waste delivered in the course of medicinal services exercises conveys a higher potential for disease and damage than some other sort of waste. ${ }^{2}$ Roughly $75-90 \%$ of the bio-therapeutic waste is non-perilous and as safe as some other civil waste. The rest of the $10-25 \%$ is perilous and can be damaging to people or creatures and injurious to the condition. It is critical to understand that if both these sorts are combined then the entire waste progresses toward becoming harmful. ${ }^{3}$ It is evaluated that yearly around 0.33 million tons of health center waste is created in India and, the quantum of waste ranges from 0.5 to $2.0 \mathrm{~kg}$ for each bed per day. ${ }^{4}$

All Bio-medical waste generated in the hospitals and health facilities ought to be arranged off entirely in agreement with the Bio-medical waste management guidelines 2016. Schedule I of which portrays the classes of Bio-restorative waste their treatment and transfer methods. ${ }^{5}$ Schedule II of which depicts the shading coding, what's more, kind of compartment for transfer of Bio-therapeutic waste. In particular, there is no system to guarantee that all waste gathered and isolated in the hospitals is discarded by plan I and II of Bio-medicinal waste guidelines and dealing with rules. There is likewise no system for guaranteeing to squander treatment inside endorsed time limits. Biorestorative waste if not taken care of legitimately and inside the stipulated era could strike in the type of deadly disease. Extra peril incorporates pilferage amid transport and reusing of disposables without being washed. ${ }^{6}$ In some health center, there is no legitimate preparing of the representatives in unsafe waste administration. This demonstrates the absence of even fundamental mindfulness among hospital workforce with respect to the safe transfer of Bio-Therapeutic waste. Keeping in see the above situation, the present thinks about has been embraced to survey the information concerning parts of Bio-Medical waste among the staff of an extensive paediatric hospital with 254 beds which provides access to tertiary health care services in Kashmir valley (J\&K).

\section{Materials and Methods}

Study Setting and Design: This cross-sectional study involved assessment of awareness among medical and paramedical staff of associated hospitals of GMC Srinagar regarding biomedical waste management. For this reason, the team of public health specialists visited paediatric hospital associated with GMC Srinagar.

Ethical Permission: Prior permission from the Institutional Ethical committee of Government Medical College, Srinagar was obtained. 
Data Collection: Following the visit to the Paediatric hospital, informed consent was obtained from the Medical Superintendent Paediatric Hospital to conduct the study. As per the protocol drafted before the commencement of the study, a total of $20 \%$ sample of the total staff on the roll involved with practises of biomedical waste management for the investigation were included in the study.. A total of 25 interviews were conducted among different cadre staff which included five doctors, five staff nurses, five pharmacists, five laboratory technicians and five sanitary personnel participated. The respondents were chosen by simple random sample among the roll. A written informed consent was obtained from the respondents before acquiring the data through a pre-outlined pre-tested survey questionnaire. The survey comprises of information with respect to biomedical waste handling guidelines 2016 [4].The questions were related to Colour coding, biohazard image, class of biomedical waste, perilous and non-hazardous squander, squander treatment and transfer strategies and so forth.

Analysis: The outcomes were expressed as frequency and percentage.

\section{Results}

Majority 18 (72\%) of the participants were unaware of any existing guidelines for bio-medical waste management in the hospital. Only $7(29.2 \%)$ participants were aware of existing 2016 BMW guidelines. Five (20.8\%) responded BMW Committee as the existing guidelines for the BMW waste management. Two (8.3\%) respondents said that there are no such existing guidelines followed in the hospital. Most of the participants $15(62.5 \%)$ responded that they have operational guidelines/manuals/any literature related to disposal of BMW. All most all the participants mentioned the type of waste material generated in their wards, laboratories and hospital in general. (Culture media, human anatomical waste, chemical waste, blood bags, culture media, dressing materials, swabs, polythene, municipal waste, sharps, needles etc.) All the participants $25(100 \%)$ responded having segregation of BMW in the wards, laboratories and hospital. When the participants were asked about who is responsible to segregate biomedical waste from the wards/labs etc. There were multiple answers. Most of the participants feel the laboratory incharge and staff nurses are the person responsible. A quarter of participants responded that sanitary personnel are responsible for BMW segregation. Only one participant said that the person who generated the waste is responsible for its segregation. All the participants $25(100 \%)$ responded having use of colour coded bins for BMW segregation in the hospital. Fourteen $(56 \%)$ responded use of 4 bins, $9(36 \%)$ responded use of 5 bins and $2(8 \%)$ responded use of only 3 bins for BMW segregation. Most of the participants responded that BMW is collected in colour coded bags and bins from the wards/laboratories etc. Some of the participants responded that sanitation staff collects BMW from the wards/laboratories. Few said that cart wheel trolleys are used. When the participants were asked about who transport BMW from wards/Laboratories, 17 (68\%) responded that it's the sweeper who transports the BMW while $8(32 \%)$ responded that sanitary personnel transport the same. [Table 1]

Table 2 shows that 13 (52\%) participants were aware of BMW committee in the hospital, thirteen (52\%) participants were aware of BMW management team in the hospital. Fifteen $(60 \%)$ participants were aware of Infectious control committee in the hospital while sixteen $(64 \%)$ participants were aware of Infectious control team in the hospital. Nine $(37.5 \%)$ participants responded having received any training on BMW among which $7(29.2 \%)$ have received it for 1 day and $2(8.3 \%)$ have received the training for 1 week respectively. Seven $(29.2 \%)$ responded having received training from Department of Community Medicine, GMC, Srinagar. All the participants $25(100 \%)$ were aware of risks of biomedical waste like HIV, Hepatitis B, Hepatitis C, Tetanus. Twenty-two (88\%) participants responded having received any kind of vaccines like H1N1, Hepatitis B and tetanus. Most of the vaccines were provided by Hospital authorities. Nine $(37.5 \%)$ participants were aware of the standard procedures used at the time of spillage of blood/body fluids. Most of the participants were unaware of standard procedures to be taken at the time of mercury spills. They responded that there is use of digital manometers and thermometers in the hospital, so chance of mercury spill is impossible. Nine $(37.5 \%)$ participants said that Blood spill kits are available in the hospital while 20 (83.35) were unaware of availability of mercury kits in the hospital. On asking about the management of liquid waste management, Majority of the participants were having poor knowing expect a quarter, who mentioned use of sodium hypochlorite solution in liquid waste and sharp waste management.

Table 1: Knowledge of hospital staff about some important aspects of waste disposal

\begin{tabular}{|l|c|c|c|c|c|}
\hline \multicolumn{1}{|c|}{ Questions } & $\begin{array}{c}\text { Doctor } \\
\mathbf{n = 5}\end{array}$ & $\begin{array}{c}\text { Nurses } \\
\mathbf{n = 5}\end{array}$ & $\begin{array}{c}\text { Pharmacists } \\
\mathbf{n = 5}\end{array}$ & $\begin{array}{c}\text { Laboratory } \\
\text { Technicians } \\
\mathbf{n = 5}\end{array}$ & $\begin{array}{c}\text { sanitary } \\
\text { personnel } \\
\mathbf{n = 5}\end{array}$ \\
\hline $\begin{array}{l}\text { Existence of BMW } \\
\text { management and handling } \\
\text { guidelines 2016 }\end{array}$ & 1 & 1 & 1 & 2 & 2 \\
$(40 \%)$ & $(20 \%)$ & $(20 \%)$ & $(40 \%)$ \\
\hline $\begin{array}{l}\text { Operational guidelines } \\
\text { related to disposal of BMW }\end{array}$ & 2 & 3 & 3 & 3 & 4 \\
\hline Categories of waste & 4 & $(40 \%)$ & $(60 \%)$ & $(60 \%)$ & $(80 \%)$ \\
\hline
\end{tabular}




\begin{tabular}{|l|c|c|c|c|c|}
\hline $\begin{array}{l}\text { Segregation of BMW in the } \\
\text { wards }\end{array}$ & $\begin{array}{c}5 \\
(100 \%)\end{array}$ & $\begin{array}{c}5 \\
(100 \%)\end{array}$ & $\begin{array}{c}5 \\
(100 \%)\end{array}$ & $\begin{array}{c}5 \\
(100 \%)\end{array}$ & $\begin{array}{c}5 \\
(100 \%)\end{array}$ \\
\hline Storage of hazardous waste & 4 & 4 & 4 & 3 & 5 \\
& $80 \%$ & $80 \%$ & $80 \%$ & $(60 \%)$ & $(100 \%)$ \\
\hline Bio-hazard symbol & 5 & 5 & 5 & 5 & 5 \\
& $(100 \%)$ & $(100 \%)$ & $(100 \%)$ & $(100 \%)$ & $(100 \%)$ \\
\hline $\begin{array}{l}\text { Waste segregation in color- } \\
\text { coded containers }\end{array}$ & 5 & 5 & 5 & 5 & 5 \\
\hline $\begin{array}{l}\text { Maximum storage time of } \\
\text { hazardous waste }\end{array}$ & $(100 \%)$ & $(100 \%)$ & $(100 \%)$ & $(100 \%)$ & $(100 \%)$ \\
\hline Waste disposal methods & 3 & 4 & 4 & 4 & 5 \\
& $(60 \%)$ & $(80 \%)$ & $(80 \%)$ & $(80 \%)$ & $(100 \%)$ \\
\hline $\begin{array}{l}\text { Disease spread by improper } \\
\text { hospital waste } \\
\text { management }\end{array}$ & 5 & 4 & 3 & 3 & 4 \\
\hline $\begin{array}{l}\text { Non-hazardous waste } \\
\text { storage }\end{array}$ & $(100 \%)$ & $(80 \%)$ & $(60 \%)$ & $(60 \%)$ & $(80 \%)$ \\
\hline $\begin{array}{l}\text { Correct method of treatment } \\
\text { \& disposal }\end{array}$ & $\begin{array}{c}(60 \%) \\
(100 \%)\end{array}$ & $\begin{array}{c}5 \\
(100 \%)\end{array}$ & $\begin{array}{c}5 \\
(100 \%)\end{array}$ & $\begin{array}{c}5 \\
(80 \%)\end{array}$ \\
\hline
\end{tabular}

Table 2: Knowledge of hospital staff about some important aspects of waste disposal

\begin{tabular}{|c|c|c|c|c|c|}
\hline Questions & $\begin{array}{c}\text { Doctor } \\
\mathbf{n}=5\end{array}$ & $\begin{array}{c}\text { Nurses } \\
n=5\end{array}$ & $\begin{array}{c}\text { Pharmacists } \\
n=5\end{array}$ & $\begin{array}{c}\text { Laboratory } \\
\text { Technicians } \\
n=5\end{array}$ & $\begin{array}{c}\text { Sanitary } \\
\text { personnel } \\
n=5\end{array}$ \\
\hline BMW committee in the hospital & $\begin{array}{c}4 \\
(80 \%)\end{array}$ & $\begin{array}{c}1 \\
(20 \%)\end{array}$ & $\begin{array}{c}1 \\
(20 \%)\end{array}$ & $\begin{array}{c}4 \\
(80 \%)\end{array}$ & $\begin{array}{c}3 \\
(60 \%)\end{array}$ \\
\hline BMW management team & $\begin{array}{c}4 \\
(80 \%) \\
\end{array}$ & $\begin{array}{c}1 \\
(20 \%)\end{array}$ & $\begin{array}{c}1 \\
(20 \%) \\
\end{array}$ & $\begin{array}{c}4 \\
(80 \%) \\
\end{array}$ & $\begin{array}{c}3 \\
(60 \%) \\
\end{array}$ \\
\hline Infectious control committee & $\begin{array}{c}4 \\
(80 \%)\end{array}$ & $\begin{array}{c}2 \\
(40 \%)\end{array}$ & $\begin{array}{c}1 \\
(20 \%)\end{array}$ & $\begin{array}{c}4 \\
(80 \%) \\
\end{array}$ & $\begin{array}{c}4 \\
(80 \%) \\
\end{array}$ \\
\hline Infectious control team & $\begin{array}{c}4 \\
(80 \%)\end{array}$ & $\begin{array}{c}2 \\
(40 \%) \\
\end{array}$ & $\begin{array}{c}2 \\
(40 \%) \\
\end{array}$ & $\begin{array}{c}4 \\
(80 \%) \\
\end{array}$ & $\begin{array}{c}4 \\
(80 \%) \\
\end{array}$ \\
\hline Training on BMW & $\begin{array}{c}1 \\
(20 \%)\end{array}$ & $\begin{array}{c}1 \\
(20 \%)\end{array}$ & $\begin{array}{c}1 \\
(20 \%) \\
\end{array}$ & $\begin{array}{c}1 \\
(20 \%) \\
\end{array}$ & $\begin{array}{c}5 \\
(100 \%) \\
\end{array}$ \\
\hline Aware of risks of biomedical waste & $\begin{array}{c}5 \\
(100 \%)\end{array}$ & $\begin{array}{c}5 \\
(100 \%)\end{array}$ & $\begin{array}{c}5 \\
(100 \%)\end{array}$ & $\begin{array}{c}5 \\
(100 \%)\end{array}$ & $\begin{array}{c}5 \\
(100 \%)\end{array}$ \\
\hline Received any kind of vaccines & $\begin{array}{c}5 \\
(100 \%)\end{array}$ & $\begin{array}{c}4 \\
(80 \%)\end{array}$ & $\begin{array}{c}4 \\
(80 \%)\end{array}$ & $\begin{array}{c}4 \\
(80 \%)\end{array}$ & $\begin{array}{c}5 \\
(100 \%)\end{array}$ \\
\hline $\begin{array}{l}\text { Standard procedures used at the time of } \\
\text { spillage of blood/body fluids }\end{array}$ & $\begin{array}{c}1 \\
(20 \%) \\
\end{array}$ & $\begin{array}{c}2 \\
(40 \%) \\
\end{array}$ & $\begin{array}{c}1 \\
(20 \%) \\
\end{array}$ & $\begin{array}{c}2 \\
(40 \%) \\
\end{array}$ & $\begin{array}{c}3 \\
(60 \%) \\
\end{array}$ \\
\hline Blood spill kits availability & $\begin{array}{c}2 \\
(40 \%) \\
\end{array}$ & $\begin{array}{c}1 \\
(20 \%)\end{array}$ & $\begin{array}{c}1 \\
(20 \%)\end{array}$ & $\begin{array}{c}1 \\
(20 \%)\end{array}$ & $\begin{array}{c}4 \\
(80 \%)\end{array}$ \\
\hline $\begin{array}{l}\text { Management of liquid waste } \\
\text { management }\end{array}$ & $\begin{array}{c}1 \\
(20 \%)\end{array}$ & $\begin{array}{c}0 \\
(0 \%) \\
\end{array}$ & $\begin{array}{c}0 \\
(0 \%) \\
\end{array}$ & $\begin{array}{c}1 \\
(20 \%)\end{array}$ & $\begin{array}{c}3 \\
(60 \%)\end{array}$ \\
\hline
\end{tabular}

\section{Discussion}

The present study was conducted to assess the awareness of medical and non-medical staff of a Paediatric Tertiary care hospital associated with Government Medical College, Srinagar. The awareness and knowledge about current BMW guidelines 2016 was highest among Laboratory technicians and sanitary personals. The sanitary personals had also better awareness about existing operational guidelines in the hospital and proper waste disposal methods. This may be due to the fact that sanitary staff underwent many trainings recently on BMW Management at Department of Community Medicine, GMC, Srinagar which may have increased their awareness and knowledge about BMW guidelines 2016. ${ }^{4}$ Similar findings were reported by Dehghani et al, 2008 in their study conducted in a hospital of Iran, ${ }^{7}$ Massrouji et al, 2001 in their study on Health workers in Gaza Governorates where there was a positive attitudes towards instructions need for training and the development of medical waste management system $^{8}$ and Patil G et al. ${ }^{9}$ Knowledge about different categories of waste, proper segregation of BMW in wards and storage of hazardous waste was reported by almost all the participants. Similar findings were reported by Sarsour A et al in their study on health personnel's who had adequate knowledge about different 
categories of waste and proper segregation of BMW in wards. ${ }^{6}$ It has been observed in our study that sanitary staff and laboratory technicians were having better knowledge than doctors and nurses about BMW segregation and disposal. Our findings are contradictory with the previous studies done by Saini et al. and Mathur et al. who reported better awareness and knowledge of BMW management among Doctors and Nurses than Laboratory technicians and sanitary personals. ${ }^{10,11}$ They stated that higher education plays an important role in awareness and understanding of BMW management guidelines, but in our study, it is not the case. We are of the view that education plays a part in awareness of individuals but it's the better understanding of the hazards of BMW and practising waste management guidelines over and again that makes a significant difference.

Furthermore, sanitary personals and laboratory technicians were well aware of and had knowledge of presence of BMW committee and BMW management team in the hospital premises. They also were aware about the presence of Infectious control committee and team in the hospital. Contradictory to it, doctors and nursing staff had poor knowledge and awareness of the same. Among the study participants, only sanitary staff had undergone training workshops on BMW management. All the participants were well aware of the risk of infections from BMW. Doctors and sanitary personals were having better vaccination status than those of other participants. Pandit et al. reported in their study about better awareness of risks from BMW among doctors and poor knowledge among sanitary personals which contradicts our study. ${ }^{12}$ Similar finding was also reported by SMS khan et al in their study conducted in one of the associated hospital of Government Medical College, Srinagar. ${ }^{13}$ Moreover, Deo et al. and Das NK et al reported better awareness and knowledge of BMW management among paramedical staff, laboratory technicians and sanitary personals which is in accordance with our study. ${ }^{14,15}$

The following are the recommendation arrived at from the findings: Though the practise of 3Rs (recycle, reuse, reduce) has some obstacles as far as BMW is concerned, reduction of BMW production can be effectively implemented. Periodic in-service training to medical and para-medical staff with the help of experts can be done for this purpose. Segregation of BMW with colour coding must be strictly enforced. Proper training at periodic intervals, especially in-service training, is one of the major step to be implemented in proper handling of BMW.

\section{Conclusion}

The sanitary personals and laboratory technicians were seen to be great in theoretical knowledge of rules, legislations and public health importance of BMW management rules 2016. While for doctors and nursing staff, the reverse was true. There is a need for regular training of the staff regarding updated BMW rules.

\section{Limitations of the Study}

In this study we took only $20 \%$ of the sample from the available health staff members as it was difficult for the investigators to collect data individually on each staff members keeping in view the busy functioning of the hospital. Duration of service among the staff members were not taken into account as this may affect the variability of results of this study. Furthermore, education level of the sample was assumed to be as per their professional position and functioning at the hospital.

\section{What this Study adds to the Literature}

The study demonstrated the knowledge and practise of BMW management among health care professionals in a tertiary care hospital of Kashmir valley. In this study we reported the existing gaps in the hospital management system and training of health professionals regarding BMW management. The results of the study were shared with the medical superintendent of GB Pant Children's Hospital for early compliance.

\section{Acknowledgement}

Authors are highly grateful to the Principal/Dean, Government Medical College, Srinagar and Medical Superintendent G.B. Pant Children Hospital for their support and timely permission to conduct the study.

\section{Conflict of Interest: None}

\section{Funding: None}

\section{References}

1. K Park. Park's Textbook of Preventive and Social Medicine, 21st ed. Jabalpur: Bhanot Publishers; 2011. P 730.

2. Singh VP, Biswas G, Sharma JJ. Biomedical Waste Management - An Emerging Concern in Indian Hospitals. IJFM\&T. 2007;1(1):39-44.

3. Patil AD, Shekdar AV. Health-care waste management in India. J Environ Manag. 2001;63(2):211-220.

4. Ministry of Environment Forest and Climate Change : Government of India. Bio-Medical Waste Management Rules, 2016. Gaz India, Extraordinary, Part II, Sect 3, Sub-section [Internet]. 2016;(i):1-37. Available from: http://mpcb.gov.in/biomedical/pdf/BMW_Rules_2016.pdf

5. National AIDS Control Organisation. Manual of Hospital infection control, New Delhi,1998;50-6.

6. Saini S, Nagarajan SS, Sharma RK. Knowledge, attitude and practices of bio-medical waste management amongst staff of a tertiary level hospital in India. J Acad Hosp Admin. 2005;17(2):1-12.

7. Dehghani M, Azam K, Changani F, Dehghani F. Assessment of Medical waste Management in Educational Hospitals of Tehran University Medical Science. Iran J Environ Health Sci Eng. 2008;5(2):131-136.

8. Massrouji M (2001). Medical waste and health workers in Gaza governorates. East Mediterr Health J. 2001;7:1017-1024.

9. Patil G. Pokhrel K. Biomedical solid waste management in an Indian hospital: a case study. Waste Manage. 2005;25:592599.

10. Sarsour A, Ayoub A, Lubbad I, Omran A, Shahrour I. Assessment of Medical Waste Management within Selected Hospitals in Gaza Strip Palestine : A Pilot Study. Int J Sci Res Environ Sci. [Internet]. 2014;2(5):164-173. Available from: http://dx.doi.org/10.12983/ijsres-2014-p0164-0173 
11. Mathur V, Dwivedi S, Hassan MA. Knowledge, Attitude and Practices about Biomedical Waste Management among Health Care Personnel: A Cross Sectional Study. Indian J Community Med. 2011;36(2):143-145.

12. Pandit NB, Mehta HK, Kartha GP. Management of biomedical waste: awareness and practices in a district of Gujarat. Indian J Public Health. 2005;49(4):245-247.

13. S. muhammad salim khan, muneer ahmad masoodi waseem qureshi. Current practices of bio-medical waste management in government medical college associated S.M.H.S Hospital, Srinagar, J\&K, India. JK-practitioner. 2004;11(3):206-209.

14. Deo D, Tak SB \&Munde SS. A study of Knowledge Regarding Biomedical Waste Management among Employees of a Teaching Hospital in Rural Area. J ISHWM. 2006;5(1):12-16.
15. Das NK, Prasad S, Jayaram K. A TQM approach to implementation of handling and management of hospital waste in Tata Main Hospital. Issued by Hospital Waste Management Committee, T.M.H. 2001;11-12(1-2):75-78.

How to cite this article: Khan S. M. S, Saleem S. M, Mukhtar M, Quansar R. Biomedical waste management practices at apaediatric tertiary care hospital of Kashmir valley. Indian $\mathrm{J}$ Forensic Community Med. 2018;5(4):231-235. 